\title{
Proteome profiling of exosomes derived from plasma of heifers with divergent genetic merit for fertility
}

\author{
Yong Qin Koh, ${ }^{*}$ Hassendrini N. Peiris, ${ }^{*}$ Kanchan Vaswani, ${ }^{*}$ Fatema B. Almughlliq, ${ }^{*}$ Susanne Meier, $\dagger$ \\ Chris R. Burke, † John R. Roche,†‡ Charlotte B. Reed,† Buddhika J. Arachchige, ${ }^{*}$ Sarah Reed, ${ }^{*}$ \\ and Murray D. Mitchell*1 \\ *University of Queensland Centre for Clinical Research, Faculty of Medicine, The University of Queensland, Brisbane, Queensland 4029, \\ Australia \\ †DairyNZ Ltd., Private Bag 3221, Hamilton 3240, New Zealand \\ ¥School of Biological Sciences, University of Auckland, Private Bag 92019, Auckland 1142, New Zealand
}

\begin{abstract}
The current study evaluated exosomes isolated from plasma of heifers bred to have high or low fertility through developing extreme diversity in fertility breeding values, however, key animal traits (e.g., body weight, milk production, and percentage of North American genetics) remained similar between the 2 groups. The exosomes were isolated by a combined ultracentrifugation and size exclusion chromatography approach and characterized by their size distribution (nanoparticle tracking analysis), morphology (transmission electron microscopy), and presence of exosomal markers (immunoblotting). In addition, a targeted mass spectrometry approach was used to confirm the presence of 2 exosomal markers, tumor susceptibility gene 101 and flotillin 1 . The number of exosomes from plasma of high fertility heifers was greater compared with low fertility heifers. Interestingly, the exosomal proteomic profile, evaluated using mass spectrometry, identified 89 and 116 proteins in the high and low fertility heifers respectively, of which 4 and 31 were unique, respectively. These include proteins associated with specific biological processes and molecular functions of fertility. Most notably, the tetratricopeptide repeat protein 41-related, glycodelin, and kelch-like protein 8 were identified in plasma exosomes unique to the low fertility heifers. These proteins are suggested to play a role in reproduction; however, the role of these proteins in dairy cow reproduction remains to be elucidated. Their identification underscores the potential for proteins within exosomes to provide information on the fertility status and physiological condition of the cow. This may
\end{abstract}

Received November 24, 2017

Accepted March 16, 2018

${ }^{1}$ Corresponding author: murray.mitchell@uq.edu.au potentially lead to the development of prognostic tools and interventions to improving dairy cow fertility.

Key words: bovine, plasma, fertility, reproduction, exosomes

\section{INTRODUCTION}

Dairy cows with good fertility and reproductive performance are vital for the profitability and sustainability of dairy farms, especially in seasonal-calving pasture-based systems (Burke and Verkerk, 2010). As a consequence of the increased metabolic pressure for milk production in past decades, fertility of the dairy cow has decreased (Roche et al., 2011). Furthermore, an inflammation through immune (Formigoni and Trevisi, 2003; Piccinini et al., 2004) or infectious (McDougall et al., 2007) challenge can have long-term consequences for the fertility of dairy cows. This peripartum inflammatory state likely contributes to the decline in fertility and reproductive success by disrupting endocrine signaling, negatively affecting uterine homeostasis, and invoking perturbations in ovarian function and oocyte development (Karsch et al., 2002; Bromfield et al., 2015).

It has recently been established that exosomes can mediate inter- and intracellular signaling under normal and pathological conditions through the transfer of bioactive molecules (e.g., proteins and microRNA) that can modulate the biological function of the recipient cells (e.g., immune response, cellular adhesion, development, proliferation, and metabolism; Corrado et al., 2013; McGough and Vincent, 2016; Crookenden et al., 2017). Several studies have identified the involvement of exosomes in providing autocrine (i.e., local signals between the same cell type, such as cancer cells; Weaver, 2017), paracrine (i.e., local signals between different cell types, such as between epithelial cancer cells and stromal cells; Heneberg, 2016), and endocrine (i.e., distant signals between many types of cells usually 
carried in bodily fluids, such as blood; Zduriencikova et al., 2015) signaling. Exosomes are membranous nanovesicles of endocytic origin that are defined by characteristics such as size, density, and morphology as well as the presence of exosomal markers [e.g., tumor susceptibility gene (TSG) 101 and flotillin 1; Lötvall et al., 2014]. Concomitant changes in the concentration or the content of exosomes may provide informative details of the overall health condition of the animal, including the possible physiological status underlying fertility.

To improve our knowledge in key areas of dairy cow reproductive physiology, a long-term project was initiated using cows with similar key animal traits (e.g., BW, milk production, and percentage of North American genetics) but with extreme diversity in their EBV for fertility. It was envisaged that the underlying physiological basis of low-fertility heifers could be elucidated through the investigation of the content (e.g., proteins) encapsulated by exosomes isolated from the plasma of 2 cohorts of heifers that were identified to be of either low or high fertility. We hypothesized that heifers selected on the basis of differential fertility EBV would have exosomal signatures in plasma representative of their fertility genotype.

\section{MATERIALS AND METHODS}

\section{Animals and Management}

Heifers used in this study were part of a larger experiment $(\mathrm{n}=60$ Holstein-Friesian heifers) from a recently established fertility animal model described by Meier et al. (2017). From this larger group, 24 heifers were identified as being either high fertility $(\mathrm{n}=12)$ or low fertility $(n=12)$ based on the extreme diversity in their EBV for fertility but being similar in genetic character for other key traits (e.g., BW, milk production, and percentage of North American genetics). The EBV for fertility is measured using 8 predictor traits. The predictor traits used to estimate the fertility breeding values include whether cows are mated within $21 \mathrm{~d}$ of the planned start of mating in first-, second-, and thirdparity cows (expressed as a binomial trait); whether cows calved in the first $42 \mathrm{~d}$ after the planned start of calving in second-, third-, and fourth-parity cows (as a binomial trait); and milk volume in a cow's first lactation and BCS in a cow's first lactation at 60 DIM. The details of the genetic merit of the 24 heifers are presented in Table 1. All heifers used in the current study were postpubertal and had expressed a minimum of 1 spontaneous estrus (Meier et al., 2017). To minimize interventions and to align with other studies to better understand the underlying drivers of fertility in dairy cattle, the timing of sampling was aligned with an estrus event stimulated with prostaglandins as described by Reed et al. (2017). The animals and their management as well as the procedures for sample collection were managed by DairyNZ Ltd. (Hamilton, New Zealand) with approval by the Ruakura Animal Ethics Committee (AEC 13574 and 13934).

\section{Blood Collection}

Blood was drawn from a jugular vein into EDTA Vacutainer tubes (Greiner Bio-One, Kremsmunster, Austria). The tubes were then centrifuged at 1,120 $\times g$ for $12 \mathrm{~min}$ at $4^{\circ} \mathrm{C}$, and the plasma aspirated was stored at $-80^{\circ} \mathrm{C}$.

\section{Exosome Isolation from EDTA Plasma}

Exosomes were isolated by coupling ultracentrifugation and size exclusion chromatography as described by Almughlliq et al. (2017). In brief, plasma (10 mL) of high- $(\mathrm{n}=12)$ and low- $(\mathrm{n}=12)$ fertility heifers was diluted with an equal volume of PBS (Gibco, Life Technologies Australia Pty Ltd., Mulgrave, Victoria, Australia) and centrifuged at 2,000 $\times \mathrm{g}$ for $30 \mathrm{~min}$ at $4^{\circ} \mathrm{C}, 12,000 \times g$ for $30 \mathrm{~min}$ at $4^{\circ} \mathrm{C}$, and at $100,000 \times g$ for $75 \mathrm{~min}$ at $4^{\circ} \mathrm{C}$. It was then filtered through a $0.22-$ $\mu \mathrm{m}$ polyethersulfone membrane filter (Corning Inc., Corning, NY) and then ultracentrifuged at 100,000 $\times$ $g$ for $120 \mathrm{~min}$. The pellet was reconstituted in $500 \mu \mathrm{L}$ of PBS and layered on a $\mathrm{qEV}$ size exclusion column (Izon Science, Christchurch, New Zealand). Fractions of $500 \mu \mathrm{L}$ were collected in separate tubes $(\mathrm{n}=16)$ per the manufacturer's instructions. The 16 fractions were concentrated using a vacuum concentrator (Eppendorf Concentrator Plus, Eppendorf, Hamburg, Germany) for $1.5 \mathrm{~h}$ at room temperature and stored at $-80^{\circ} \mathrm{C}$ until further analyses.

\section{Nanoparticle Tracking Analysis}

The nanoparticle tracking analysis was conducted using a NanoSight (Salisbury, UK) NS500 instrument (NanoSight NTA 3.0 Nanoparticle Tracking and Analysis Release Version Build 0064) as previously described (Kobayashi et al., 2014; Salomon et al., 2014). This method was used to determine the size distribution and total exosome particle number of the EDTA plasma.

\section{Western Blot Analysis}

The proteins were extracted from the isolated exosomes using radioimmunoprecipitation assay buffer (Sigma-Aldrich, Castle Hill, New South Wales, Austra- 
lia) and were incubated for $10 \mathrm{~min}$ at $70^{\circ} \mathrm{C}$ in a reducing agent (NuPAGE Sample Reducing Agent, Life Technologies Australia Pty Ltd., Mulgrave, Victoria, Australia) and a loading buffer (NuPAGE lithium dodecyl sulfate sample buffer, Life Technologies Australia Pty Ltd.). Electrophoresis was performed on the reduced proteins loaded and separated in NuPAGE Novex 4 to $12 \%$ Bis-Tris Gels. Proteins were transferred to a polyvinyl difluoride membrane using the Trans-Blot Turbo system (Bio-Rad Laboratories Pty Ltd., Gladesville, NSW, Australia). Membranes were blocked for $1 \mathrm{~h}$ in blocking solution $[2 \%$ of BSA in PBST $(0.001 \%$ Tween 20 in PBS; Sigma-Aldrich)]. Membranes were probed with primary antibody anti-flotillin 1 [1:500; goat polyclonal, ab13493, epitope (SISQVNHKPLRTA); Abcam, Cambridge, UK], primary antibody anti-TSG101 (1:500; rabbit polyclonal, ab50582; Abcam), and primary antibody anti-CD63 (1:1,000; rabbit polyclonal, EXOAB-CD63A-1; System Biosciences, Palo Alto, CA) followed by secondary donkey anti-goat IgG-horseradish peroxidase (1:1,000; sc-2020; Santa Cruz Biotechnology, Dallas, TX) and anti-rabbit IgG (1:1,000; A0545; Sigma-Aldrich). SuperSignal West Dura-Extended Duration Substrate (Thermo Fisher Scientific, Waltham, MA) was used to visualize the proteins on X-ray film (Agfa, Mortsel, Belgium) and developed using a Konica Minolta SRX-101A processor (Konica Minolta Medical and Graphic Inc., Tokyo, Japan).

\section{Transmission Electron Microscopy}

For electron microscopy analysis, the samples were adsorbed on a formvar-coated copper grid for $2 \mathrm{~min}$, washed briefly in ultrapure water (Life Technologies Australia Pty Ltd.), and negatively stained with $1 \%$ uranyl acetate. The samples were then viewed using a Jeol 1010 (Tokyo, Japan) transmission electron microscope operating at $80 \mathrm{kV}$, and images were captured

Table 1. Genetic indices of the animal model (group means and SEM of these means)

\begin{tabular}{|c|c|c|c|c|c|}
\hline \multirow{2}{*}{ Parameter } & \multicolumn{4}{|c|}{ Animal model } & \multirow{2}{*}{$t$-test } \\
\hline & \multicolumn{2}{|c|}{ High fertility $(\mathrm{n}=12)$} & \multicolumn{2}{|c|}{ Low fertility $(\mathrm{n}=12)$} & \\
\hline Age $(d)$ & 402.17 & 3.91 & 394.67 & 4.93 & 0.246 \\
\hline Breeding worth ${ }^{1}$ & 154.00 & 7.59 & 69.25 & 4.43 & $<0.0001$ \\
\hline Production worth ${ }^{2}$ & 94.87 & 8.31 & 115.78 & 5.75 & 0.0504 \\
\hline Milk fat $\mathrm{BV}^{4}$ & 17.09 & 1.42 & 22.75 & 1.32 & 0.0079 \\
\hline Protein $\mathrm{BV}^{4}$ & 25.67 & 0.91 & 25.91 & 1.22 & 0.8732 \\
\hline $\mathrm{BW} \mathrm{BV}^{4}$ & 40.10 & 2.64 & 37.08 & 2.79 & 0.4399 \\
\hline $\mathrm{BCS} \mathrm{BV}^{5}$ & 0.08 & 0.01 & -0.09 & 0.02 & $<0.0001$ \\
\hline Gestation length $\mathrm{BV}^{6}$ & -3.13 & 0.68 & -1.73 & 0.60 & 0.1394 \\
\hline North American Holstein-Friesian genes (\%) & 56.64 & 1.28 & 60.43 & 1.87 & 0.1089 \\
\hline Residual survival $\mathrm{BV}^{7}$ & 55.00 & 11.00 & 38.75 & 27.39 & 0.5875 \\
\hline
\end{tabular}

${ }^{1}$ Breeding worth is the NZ\$ net farm income/5 t of DM, which is assumed to be fed per cow per year.

${ }^{2}$ Production worth measures the ability of the cow to convert feed into profit over her lifetime (DairyNZ, 2016).

${ }^{3}$ Fertility BV is a percentage value consisting of the lactating cow's ability to start cycling (a binary trait called PM21, representing success or failure at being presented for mating in the first $21 \mathrm{~d}$ of the herd's mating period, from first-, second-, and third-parity cows), a lactating cow's ability to conceive (a binary trait called CR42, representing success or failure for recalving in the first $42 \mathrm{~d}$ of the herd's calving period, from first-, second-, and third-parity cows), and a lactating cow's calving interval, in days, from parity 1 to parity 2 (DairyNZ, 2017).

${ }^{4}$ The mating plan aimed to confine the BV for milk volume, fat, protein, BW, and ancestry (\% North American Holstein-Friesian) to be within $1 \mathrm{SD}$ and produce calves of $15 / 16$ or 16/16 Holstein-Friesian breeding.

${ }^{5}$ Body condition unit is a measure of subcutaneous fat deposits (Roche et al., 2004), calculated using records collected on 2-yr-old heifers.

${ }^{6}$ Ancestry data based on animal evaluation run following parentage checks (Feb. 2016).

${ }^{7}$ Residual survival BV represents residual or uncounted genetic merit for survival (DairyNZ, 2017).

${ }^{8}$ Total longevity BV is calculated from information derived from herd testing and herd recording software. Longevity BV is currently estimated using 4 direct and 9 predictor traits. The 4 direct traits are survival from first to second lactation, survival from first to third lactation, survival from first to fourth lactation, and survival from first to fifth lactation. The 9 predictor traits are protein yield in lactation 1, SCS in lactation 1, BCS in lactation 1, calving rate in the first $42 \mathrm{~d}$ after the planned start of calving in lactation 2 , owner opinion in lactation 1 , milking speed in lactation 1, leg conformation in lactation 1, dairy conformation in lactation 1, and udder overall in lactation 1 (DairyNZ, 2017).

${ }^{9}$ Somatic cell score is the log-transformed of the SCC, which is derived from herd testing (DairyNZ, 2017). 
with an Olympus (Tokyo, Japan) Soft Imaging Veleta digital camera.

\section{Proteomic Analysis of High- and Low-Fertility Plasma Exosomes by MS}

Sample Preparation and Desalting. Exosomes (10 $\mu \mathrm{g}$ of protein) in PBS were sonicated for $5 \mathrm{~min}$ to disrupt the exosome membrane and expose proteins for proteomic analyses by liquid chromatography-MS/ MS. In brief, each of the exosome fractions was treated with $50 \mathrm{mM}$ ammonium bicarbonate and then with 20 $\mathrm{m} M$ dithiothreitol and reduced for $1 \mathrm{~h}$ at $65^{\circ} \mathrm{C}$. The samples were then alkylated in $100 \mathrm{~m} M$ iodoacetamide at $37^{\circ} \mathrm{C}$ in the dark for $60 \mathrm{~min}$. Samples were incubated with trypsin (Sigma-Aldrich) at a 1:50 ratio overnight at $37^{\circ} \mathrm{C}$ for $18 \mathrm{~h}$, and the reaction was stopped by the addition of $0.1 \%$ formic acid. The samples were combined and desalted according to a modified version of the stage tip protocol using a 3-mm piece of an Empore C18 (octadecyl) SPE Extraction Disk (3M, Minneapolis, MN; Rappsilber et al., 2003; Vaswani et al., 2015). The eluted peptides were dried in a vacuum centrifuge before spectral acquisition.

Targeted MS Approach for the Identification of Exosome Marker. The digested protein samples were analyzed using an Eksigent 200 Micro-Liquid chromatography system coupled with a triple quadrupole 5500 mass spectrometer (AB Sciex, Redwood City, CA) as described previously (Koh et al., 2017). The TSG101 analytes (LDQEVAVDKNIELLR and DEELSSALEK) were monitored using electrospray ionization in positive-ion mode with multiple reaction monitoring using characteristic precursor-product ion transitions of mass: charge ratio $(m / z)$ for TSG101 (628.624 > 1,000.579, 855.552 , and $643.414 \mathrm{Da}$ and $560.772>747.425$, 661.268, and 574.235 Da, respectively), whereas flotillin 1 (LTGVSISQVNHKPLR and ISLNTLTLNVK) analytes were monitored using electrospray ionization in positive-ion mode with multiple reaction monitoring using characteristic precursor-product ion transitions of $m / z$ for flotillin $1(824.978>1,078.612,999.547$, and $385.256 \mathrm{Da}$ and $608.369>788.48,743.430$, and 642.382 Da, respectively). Data processing was performed using Analyst software (version 1.6.2; AB Sciex).

$M S$ for the Identification of Exosomal Cargo. The digested protein samples were analyzed using the TripleTOF 5600 mass spectrometer (ABSciex) coupled to an Eksigent (Dublin, CA) nano ultra 1D+ HPLC system. The ChromXP C18-CL TRAP $(10 \mathrm{~mm} \times 0.3$ $\mu \mathrm{m}, 120 \AA$ ) and analytical ChromXP C18 columns $(0.075 \mu \mathrm{m} \times 150 \mathrm{~mm} ; 3 \mu \mathrm{m}, 120 \AA$; Eksigent $)$ were used to separate the digested proteins. A $5-\mu \mathrm{L}$ aliquot of digested material was injected onto the column and separated with a linear gradient of 5 to $40 \%$ buffer B for 58 min (buffer A: $0.1 \%$ formic acid/water; buffer B: acetonitrile/0.1\% formic acid), 40 to $50 \%$ buffer B for $5 \mathrm{~min}$, and 50 to $95 \%$ buffer B for $10 \mathrm{~min}$ with a flow rate of $250 \mathrm{~nL} / \mathrm{min}$. The column was flushed with $95 \%$ buffer $\mathrm{B}$ for $15 \mathrm{~min}$ and re-equilibrated with $2 \%$ buffer B for 6 min. The in-depth proteomic analysis was performed using information dependent acquisition on the TripleTOF 5600 System (ABSciex, Redwood City, $\mathrm{CA}$ ) interfaced with a nanospray ion source. The source parameters were as follows (arbitrary units): curtain gas value $=25$, ion source gas $=10$, and declustering potential $=70$. A $250-\mathrm{ms}$ accumulation time was set for the time-of-flight MS survey scan and, from this scan, the 12 most intense precursor ions were selected automatically for the MS/MS analysis (accumulation time of $150 \mathrm{~ms}$ per MS/MS scan).

Protein identification was determined using ProteinPilot Software (version 4.5 beta, AB Sciex) with the Paragon algorithm and against UniProt (Bos taurus protein database). The search parameters were as follows: sample type, identification; cys alkylation, iodoacetamide; digestion, trypsin; instrument, TripleTOF 5600; special factors, none; and ID focus, biological modifications. False discovery rate was selected in the processing method, which automatically set the detected protein threshold to $0.05(10 \%)$. The low protein threshold value allowed a full range of identifications to be made, therefore providing a more comprehensive assessment of the quality of the data. The data were processed and categorized based on biological process (defined as the function of a particular protein in the context of a larger network of proteins that interact to accomplish a process at the level of the cell or organism) and molecular function (defined as the function of the protein by itself or with directly interacting proteins at a biochemical level) with the ontology and pathway analysis using the protein analysis through an evolutionary relationships tool (Panther; http://www .pantherdb.org/) and gene ontology (GO) algorithms (Mi et al., 2016).

\section{Statistical Analyses}

The statistical analyses were performed using a commercially available software package (Prism 6, GraphPad Inc., La Jolla, CA). A Mann-Whitney test was used to analyze and compare the total exosome particle number between the high- and low-fertility treatment groups. A value of $P<0.05$ was considered to be statistically significant, and the data are presented as mean $\pm \mathrm{SD}$. 


\section{RESULTS}

\section{Characterization of Exosomes Isolated from Plasma of High- and Low-Fertility Heifers}

Plasma exosomes derived from high- and low-fertility heifers were characterized using immunoblotting for the presence of exosomal markers, flotillin 1, TSG101, and CD63 proteins (representative immunoblot shown in Figure 1A). The spherical and intact morphology of the exosomes (representative vesicle shown in Figure 1B) was confirmed with transmission electron microscopy. Figure $1 \mathrm{C}$ and $\mathrm{D}$ demonstrates size distribution and particle number for both high- $(\mathrm{n}=12)$ and low- (n $=12$ ) fertility groups through nanoparticle tracking analysis (Figure 1D). The total exosome particle number (particles $/ \mathrm{mL})$ was $23 \%$ greater $(P<0.05)$ in the high-fertility heifers $\left(2.64 \times 10^{10} \pm 0.40 \times 10^{10}\right.$ particles $/ \mathrm{mL}$; mean $\pm \mathrm{SD}$ ) compared with the low-fertility heifers $\left(2.04 \times 10^{10} \pm 0.64 \times 10^{10}\right.$ particles $/ \mathrm{mL}$; mean $\pm \mathrm{SD})$.

\section{Targeted Proteomic Analysis of TSG101 Peptides of High- and Low-Fertility Plasma Exosomes}

To validate the detection of TSG101 by immunoblot (Figure 1A), we identified 2 TSG101 peptide precursors (accession no. A3KN51, bovine) with at least 3 transitions that correspond to the targeted peptide in both the high- and low-fertility plasma exosomes by a targeted proteomic approach using the triple quadrupole mass spectrometer to facilitate confident peptide identification (Yocum and Chinnaiyan, 2009). A peptide of TSG101, LDQEVAVDKNIELLR (mass selected by the first quadrupole, 628.624 Da), was detected in both the high- and low-fertility plasma exosomes (Table 2A) with 3 transitions $(1,000.579,885.552$, and 643.414 $\mathrm{Da}$ ); it corresponded with the targeted peptide (relative retention time at $5.6 \mathrm{~min})$. The peptide of TSG101, DEELSSALEK (mass selected by the first quadrupole, $560.772 \mathrm{Da})$, was also detected in both the high- and low-fertility plasma exosomes (Table 2B) with 3 transitions $(747.425,661.268$, and $574.235 \mathrm{Da})$ corresponding to the targeted peptide (relative retention time at 5.7 $\min )$.

\section{Targeted Proteomic Analysis of Flotillin 1 Peptides of High- and Low-Fertility Plasma Exosomes}

The exosome marker flotillin 1 (accession no. Q08DN8, bovine) in both the exosomes from plasma of high- and low-fertility groups was also confirmed by the targeted proteomic approach using the triple quadrupole mass spectrometer. The triple quadrupole mass spectrometer identified 2 flotillin 1 peptide precursors with at least 3 transitions that correspond to the targeted peptide from both the high- and low-fertility plasma exosomes. A peptide of flotillin 1, LTGVSISQVNHKPLR (mass selected by the first quadrupole, $824.978 \mathrm{Da}$ ), was detected in both the high- and low-fertility plasma exosomes (Table 2C) with 3 transitions (1,078.612, 999.547 , and $385.256 \mathrm{Da}$ ) that corresponded to the peptide (relative retention time at $5.6 \mathrm{~min}$ ). The flotillin 1 precursor peptide (LTGVSISQVNHKPLR) identified by MS is consistent with the peptide sequence of the flotillin 1 antibody (SISQVNHKPLRTA) used for immunoblotting (Figure 1A). The peptide of flotillin 1, ISLNTLTLNVK (mass selected by the first quadrupole, 608.369 Da), was also detected in both the high- and low-fertility plasma exosomes (Table 2D) with 3 transitions $(788.488,743.430$, and $642.382 \mathrm{Da}$ ) corresponding to the peptide (relative retention time at $5.5 \mathrm{~min}$ ).

\section{Mass Spectrometric Analysis of High- and Low- Fertility Plasma Exosomes: Proteomic Profile}

Mass spectrometric analysis, with a set false discovery rate of $5 \%$ for proteins and at least 2 peptides above the $95 \%$ confidence area, identified a total of 120 proteins in the exosomes isolated from plasma of high- and low-fertility heifers (Figure 2; Table 3; Supplemental Table S1, https://doi.org/10.3168/jds.2017-14190). The total spectra and peptide numbers for each protein of 12 individual cows from each group are presented in Supplemental Table S2 (https://doi.org/10.3168/ jds.2017-14190). There were 85 proteins in common between the 2 groups (Figure 2). Four proteins were unique to the exosomes isolated from plasma from high-fertility heifers, whereas 31 proteins were unique to the exosomes isolated from plasma from low-fertility heifers.

The proteins identified by MS were further clustered into biological processes and molecular function, as defined by the Panther classification system and GO algorithms (Table 3; Supplemental Table S1, https://doi .org/10.3168/jds.2017-14190). The protein CD5L (accession no. F1N514) was identified as common to both the plasma exosomes from high- and low-fertility heifers (Supplemental Table S1). This protein was reported by de Menezes-Neto et al. (2015) to be a suitable exosomal marker for the identification of plasma-derived exosomes by MS. Through the Panther classification system and GO algorithms, CD5L is revealed to have roles in biological processes (i.e., cellular process, localization and metabolic process) and molecular functions (i.e., catalytic activity and receptor activity). 
A

\section{High Fertility}

$\begin{array}{llllllll}\text { Fraction } & 10 & 11 & 12 & 13 & 14 & 15 & 16\end{array}$

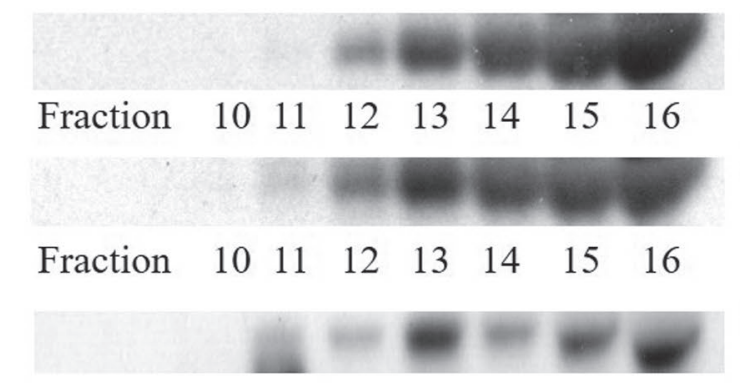

\section{Low Fertility}

B

\section{High Fertility}

Flotillin 1

TSG101

CD63

\section{Low Fertility}

Flotillin 1

$\begin{array}{llllllll}\text { Fraction } & 10 & 11 & 12 & 13 & 14 & 15 & 16\end{array}$

TSG101

$\begin{array}{llllllll}\text { Fraction } & 10 & 11 & 12 & 13 & 14 & 15 & 16\end{array}$

CD63

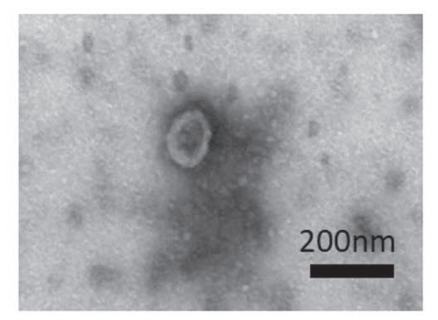

C

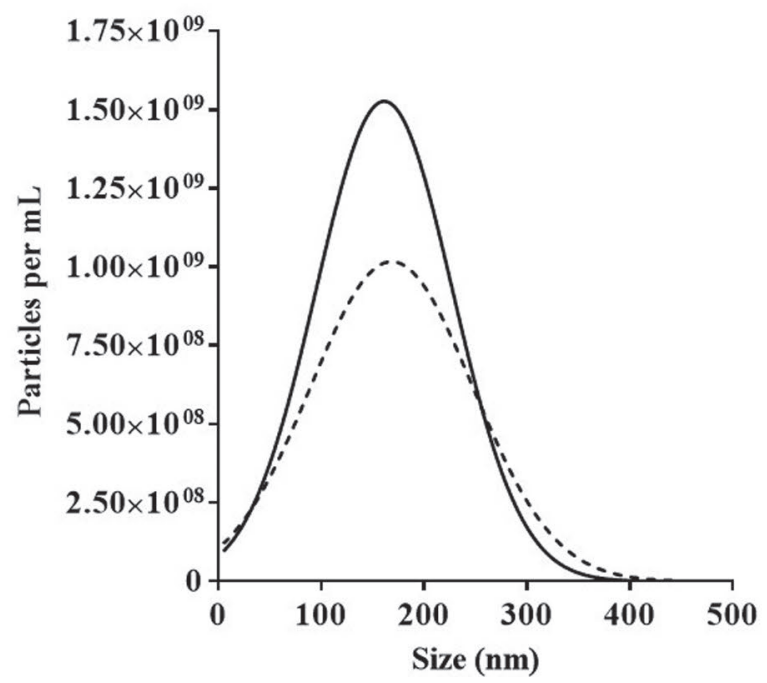

D

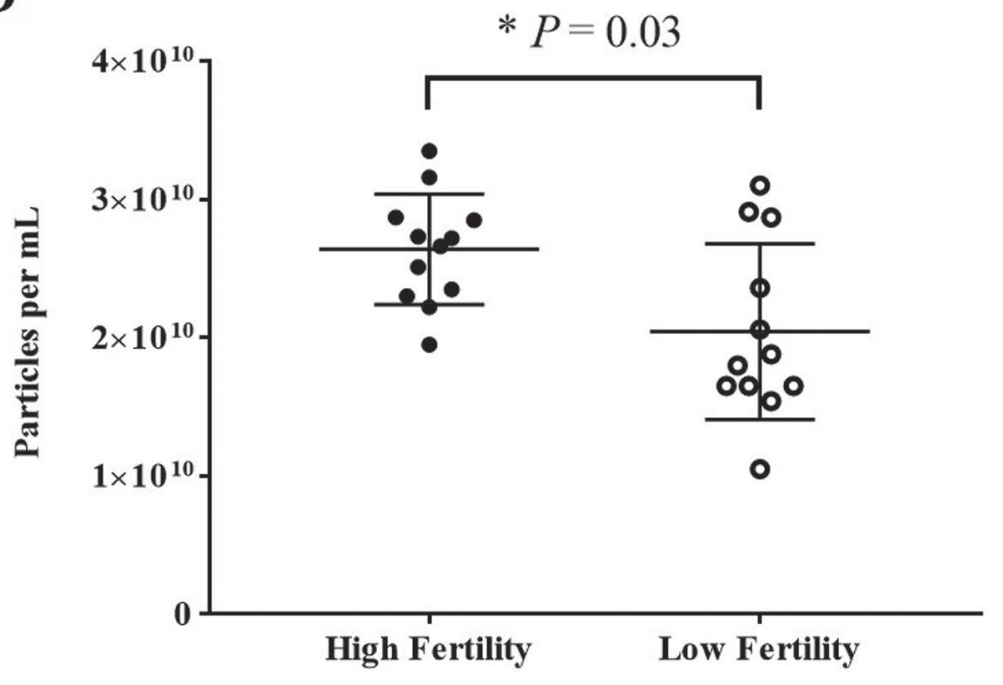

Figure 1. Characterization of exosomes isolated from plasma of high- and low-fertility heifers. (A) Representative immunoblot of exosome markers: Flotilin1, TSG101, and CD63. (B) Representative electron micrograph of exosomes. Scale bar $=100 \mathrm{~nm}$. (C) Nanosight measurement of particle size (nm) distribution of plasma exosomes from high-fertility (-) and low-fertility (- - -) heifers. (D) The total exosome particle number (particles $/ \mathrm{mL}$ ) isolated from plasma of high- and low-fertility heifers was compared. Symbols represent individual animals, and the data are presented as mean $\pm \mathrm{SD}(\mathrm{n}=12)$. 
Table 2. Triple quadrupole mass spectrometric detection of TSG101 and flotillin 1 precursor and its corresponding transitions

\begin{tabular}{|c|c|c|c|c|}
\hline Item & $\begin{array}{l}\text { First quadrupole } \\
\text { mass (Da) }\end{array}$ & $\begin{array}{c}\text { Third quadrupole } \\
\text { mass (Da) }\end{array}$ & Charge & $\begin{array}{c}\text { Retention } \\
\text { time (min) }\end{array}$ \\
\hline A3KN51_TSG101_LDQEVAVDKNIELLR & $\begin{array}{l}628.674 \\
628.674 \\
628.674\end{array}$ & $\begin{array}{r}1,000.58 \\
885.552 \\
643.414\end{array}$ & $\begin{array}{l}+3 \mathrm{y} 8 \\
+3 \mathrm{y} 7 \\
+3 \mathrm{y} 5\end{array}$ & $\begin{array}{l}5.6 \\
5.6 \\
5.6\end{array}$ \\
\hline A3KN51_TSG101_DEELSSALEK & $\begin{array}{l}560.772 \\
560.772 \\
560.772\end{array}$ & $\begin{array}{l}747.425 \\
661.268 \\
574.235\end{array}$ & $\begin{array}{l}+2 \mathrm{y} 7 \\
+2 \mathrm{~b} 6 \\
+2 \mathrm{~b} 5\end{array}$ & $\begin{array}{l}5.7 \\
5.7 \\
5.7\end{array}$ \\
\hline Q08DN8_Flotillin 1_LTGVSISQVNHKPLR & $\begin{array}{l}824.978 \\
824.978 \\
824.978\end{array}$ & $\begin{array}{r}1,078.61 \\
999.547 \\
385.256\end{array}$ & $\begin{array}{l}+3 \mathrm{y} 9 \\
+1 \mathrm{~b} 10 \\
+2 \mathrm{y} 3\end{array}$ & $\begin{array}{l}5.6 \\
5.6 \\
5.6\end{array}$ \\
\hline Q08DN8_Flotillin 1_ISLNTLTLNVK & $\begin{array}{l}608.369 \\
608.369 \\
608.369\end{array}$ & $\begin{array}{l}788.488 \\
743.43 \\
642.382\end{array}$ & $\begin{array}{l}+2 \mathrm{y} 7 \\
+1 \mathrm{~b} 7 \\
+3 \mathrm{~b} 6\end{array}$ & $\begin{array}{l}5.5 \\
5.5 \\
5.5\end{array}$ \\
\hline
\end{tabular}

Keratin, type II cytoskeletal 6A (accession no. MOQVY0) and keratin, type II cytoskeletal 1 (accession no. G3N0V2) were proteins identified as unique to plasma exosomes from high-fertility heifers (Table 3A). Through Panther and GO algorithms classification, keratin, type II cytoskeletal 6A (accession no. MOQVY0) and keratin, type II cytoskeletal 1 (accession no. G3N0V2) were found to have structural molecular activity and be mainly associated with cellular component organization or biogenesis and cellular processes. The Panther and GO algorithms also attempt to predict an uncharacterized protein (accession no. G5E5V1)

\section{$\underline{\text { High Fertility }}$}

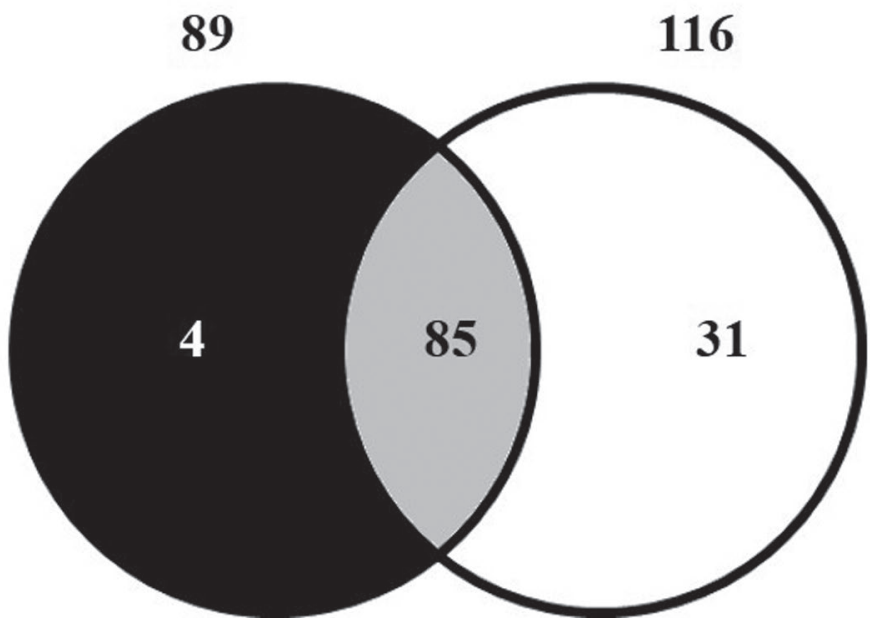

Figure 2. Proteomic analysis of exosomes isolated from the plasma of high- and low-fertility heifers. The Venn diagram illustrates the comparison between the common and unique proteins identified by liquid chromatography-MS/MS in exosomes isolated from plasma of high- and low-fertility heifers. that has been identified as unique to plasma exosomes from high-fertility heifers and assigned to have a role in stimulus response (Table 3A).

Glycodelin (accession no. G5E5H7) and Kelch-like protein 8 (accession no. E1BPB7) were unique proteins identified in plasma exosomes from low-fertility heifers (Table 3B), were mainly associated with a role in cellular and metabolic processes, and had catalytic activity. The tetratricopeptide repeat protein 41-related (accession no. F1MRZ1), a unique protein identified in plasma exosomes from low-fertility heifers, was not assigned a role for biological process and molecular function that was covered by the Panther classification system and GO algorithms.

\section{DISCUSSION}

Dairy cow fertility is important for the profitability and sustainability of dairy farms, especially in strict seasonal-calving pasture-based systems, to ensure that the cows are able to calve within the seasonal production system (Burke and Verkerk, 2010). We hypothesized that heifers selected on the basis of differential fertility EBV would have exosomal signatures in plasma representative of their fertility genotype. A greater number of exosomes were observed in the high-fertility group compared with the low-fertility group. Interestingly, the exosomes from plasma of the low-fertility group revealed greater protein abundance compared with the high-fertility group. The differences in the numbers and protein content of exosomes in the plasma may be associated with the differences in fertility breeding value. It is also plausible that differences in BCS, total longevity, and SCC score (Table 1) of the high- and low-fertility heifers could contribute to differences in the numbers and protein content of exosomes in the plasma. 
EXOSOME EVALUATION OF HIGH- AND LOW-FERTILITY HEIFERS

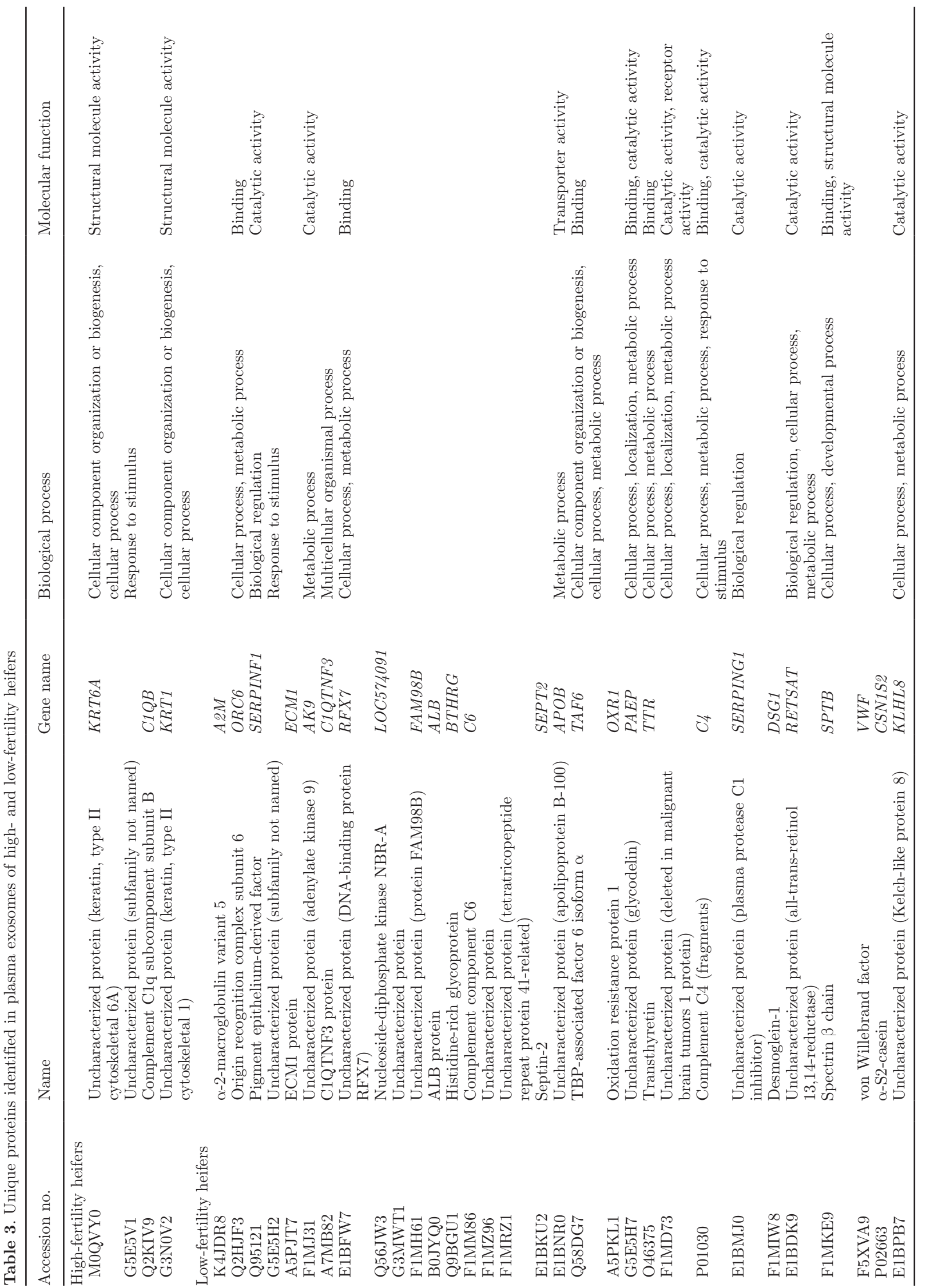


A recent study (Mitchell et al., 2016) compared the exosomes from plasma of dairy cows with divergent fertility phenotypes (fertile and subfertile). These cows differed in their genetic ancestry, with subfertile being a North American Holstein-Friesian strain (>92\% North American genetics) and fertile being a New Zealand Holstein-Friesian strain $(<23 \%$ North American genetics). In the study by Mitchell et al. (2016), the subfertile dairy cows also had fewer exosomes and a greater protein abundance encapsulated within the plasma exosomes. This finding is similar to the current study, which compared exosomes from plasma of heifers with similar genetic ancestry but with divergent fertility breeding values resulting in dairy cows with higher or lower fertility.

Koch et al. (2010) evaluated differences in proteomic content in the uterine lumen of nonpregnant and earlypregnant ewes by liquid chromatography-MS/MS and identified a unique proteomic signature in early-pregnant ewes compared with nonpregnant ewes. Exosomal differences (exosomal content-i.e., microRNA, RNA, and proteins) from exosomes isolated from uterine fluid of pregnant and cyclic ewes was investigated by Burns et al. (2014). Importantly, the differences in the exosomal profiles between the 2 groups may be dependent on the cell type from which they originate (e.g., conceptus or maternal endometrium) and could reflect the physiological or pregnancy status of ewes (Burns et al., 2014). In addition, Nakamura et al. (2016) reported that conceptus-derived exosomes from the uterine flushings of d 15 and 17 pregnant ewes contained functional proteins, including macrophage-capping protein (CAPG), aldo-keto reductase family 1, member B1 protein (AKR1B1), and interferon tau (IFNT). This study demonstrated that these exosomes upregulated the expression of several interferon-stimulated genes of endometrial epithelial cells, suggesting that exosomes released from the conceptus may be important during the attachment of the conceptus to the maternal endometrium and establishment of pregnancy.

It is well recognized that exosomes released into the extracellular space or into circulation are an important signaling system that transfers biomolecules between different cells under normal as well as pathological conditions (Koniusz et al., 2016). The proteomic profiling by Reinhardt et al. (2012) revealed that the different types of cells present in the milk compartment, including immune cells and the secretory epithelia, may contribute to protein diversity in milk exosomes. Furthermore, the same group evidenced that the milk exosome proteome changes during physiological (e.g., midlactation) and pathological conditions (e.g., mastitis; Reinhardt et al., 2013). Due to the nature of their formation, exosomes provide important functional information about the propagating cell. Hence, elucidating the biomolecules encapsulated within these exosomes can provide details about the overall health status of dairy cows, including the fertility status of dairy cows (Mitchell et al., 2016; Pohler et al., 2017).

Our mass spectrometric analysis revealed a total of 120 distinct proteins (both high- and low-fertility groups), of which 85 proteins $(70 \%)$ were common to plasma exosomes of both high- and low-fertility heifers. Interestingly, 31 proteins were identified as unique to the plasma exosomes of the low-fertility heifers and 4 were unique in high-fertility heifers.

Notably, the tetratricopeptide repeat protein 41-related (accession no. F1MRZ1), glycodelin (accession no. G5E5H7), and Kelch-like protein 8 (accession no. E1BPB7) were identified as unique to low-fertility heifers and therefore may have vital roles in fertility. The tetratricopeptide repeat protein 41-related is a protein-protein interaction module that consists of the tetratricopeptide repeat motifs, which serve as scaffolds for the assembly of different multiprotein complexes (Zeytuni and Zarivach, 2012). Increasingly, studies have indicated the association of tetratricopeptide repeat motif and its role in the regulation of reproductive development (Tranguch et al., 2005; Gray et al., 2006; Yang et al., 2006; Xu et al., 2015; Yu et al., 2016). Tsukahara et al. (1996) identified a Down syndrome-critical region of chromosome 21q22.2, which encodes a protein possessing the tetratricopeptide repeat motif. An overexpression of the gene was found to cause several morphological anomalies in the brain of a fetus with Down syndrome (Tsukahara et al., 1996). To date, no specific studies are available on the role of tetratricopeptide repeat protein 41-related in the formation of multiprotein complexes. Tetratricopeptide repeat protein 41-related was also not assigned a role for biological process and molecular function that was covered by Panther classification system and GO algorithms. However, identifying and elucidating the protein(s) in which tetratricopeptide repeat protein 41-related interacts may improve our knowledge on protein-protein interaction that is important in bovine fertility and reproduction.

Glycodelin, identified uniquely in the low-fertility heifers, is a progesterone-regulated glycoprotein that can have different functions depending on progesterone concentration at different phases of the reproductive cycle (Uchida et al., 2013). Through Panther classification system and GO, glycodelin was identified to have catalytic activity and is associated with a role in cellular and metabolic processes. Studies have shown that glycodelin is synthesized in the endometrium (Seppälä et al., 2002; Spencer et al., 2004) as well as the luteinized granulosa cells of the ovary and is present in 
follicular fluid (Glister et al., 2014; Rizos et al., 2016). The timely expression of glycodelin during reproduction, in particular fertilization and implantation, is regulated by the endocrine system (Seppälä et al., 1997; Taheripanah et al., 2017). The increased expression of glycodelin during the period of endometrial receptivity is essential for the immunologic (Alok and Karande, 2009) and hormonal (Uchida et al., 2005) regulation of reproduction. However, the presence of glycodelin during the fertilization period can cause fertilization to fail by suppressing sperm capitation and inhibit the binding of spermatozoa to the zona pellucida (Koistinen et al., 2003), thus not favoring sperm-egg fertilization and ovum formation.

Kelch-like protein 8 was also identified in exosomes from plasma of low-fertility heifers. Through the Panther classification system and GO, KLHL8 was identified to have catalytic activity and is associated with a role in cellular and metabolic processes. The KLHL8 gene was initially identified as preferentially expressed in the female gonads of fish (zebrafish and carbiomedaka), where it may play a role in oogenesis (Gautier et al., 2011). Strucken et al. (2012) demonstrated that KLHL8 could affect the nonreturn rate (defined as the percentage of inseminated cows that are pregnant at 56 $\mathrm{d}$ after service) in heifers by regulating the ovulation process and suggested the use of KLHL 8 as a candidate ovary-specific gene marker for the detection of the nonreturn rate in heifers (Strucken et al., 2012).

Our study has demonstrated that exosomes carry important messages that could reveal the fertility status and physiological condition of the cow. The current study examined the proteome of plasma exosomes from high- and low-fertility heifers using a high-throughput mass spectrometric discovery approach to unravel new information and potential candidate proteins for fertility. However, further validation of potential candidate proteins through a targeted quantification approach will further strengthen the development of those proteins as markers for fertility. A thorough investigation into the functions of exosomal protein cargo (e.g., biological processes and molecular functions) and how these biomolecules (e.g., proteins) are regulated, particularly those that affect dairy cow fertility, may reveal key biological signals that could aid the assessment of the fertility status of dairy cows. This may lead to the development of prognostic tools and interventions to improve dairy cow fertility.

\section{ACKNOWLEDGMENTS}

YQK is supported by a student scholarship from a partnership fund (DRCX1302) between the New Zea- land Ministry of Business, Innovation and Employment (Wellington, New Zealand) and New Zealand dairy farmers through DairyNZ Inc. (Hamilton, New Zealand). FBA is supported by a student scholarship from Shimadzu Corporation (Kyoto, Japan). The laboratory experiments were funded, in part, by the Australian Research Council (Canberra, Australia; grant no. ARC DP170104273 and ARC LP160101854), and the tissues investigated originated from a research platform funded by the aforementioned partnership fund (DRCX1302). We also thank the technical and farm staff at DairyNZ Ltd. for collecting the plasma samples and appreciate the scientific and technical assistance of the Australian Microscopy and Microanalysis Research Facility at the Centre for Microscopy and Microanalysis at the University of Queensland (Brisbane, Queensland, Australia).

\section{REFERENCES}

Almughlliq, F. B., Y. Q. Koh, H. N. Peiris, K. Vaswani, S. McDougall, E. M. Graham, C. R. Burke, and M. D. Mitchell. 2017. Effect of exosomes from plasma of dairy cows with or without an infected uterus on prostaglandin production by endometrial cell lines. J. Dairy Sci. 100:9143-9152.

Alok, A., and A. A. Karande. 2009. The role of glycodelin as an immune-modulating agent at the feto-maternal interface. J. Reprod. Immunol. 83:124-127.

Bromfield, J. J., J. E. Santos, J. Block, R. S. Williams, and I. M. Sheldon. 2015. Physiology and Endocrinology Symposium: Uterine infection: Linking infection and innate immunity with infertility in the high-producing dairy cow. J. Anim. Sci. 93:2021-2033.

Burke, C. R., and G. A. Verkerk. 2010. The development of reproductive management practices in New Zealand: What will the future hold in a consumer-focused, environmentally-conscious, exportdriven marketplace? Soc. Reprod. Fertil. Suppl. 67:341-355.

Burns, G., K. Brooks, M. Wildung, R. Navakanitworakul, L. K. Christenson, and T. E. Spencer. 2014. Extracellular vesicles in luminal fluid of the ovine uterus. PLoS One 9:e90913.

Corrado, C., S. Raimondo, A. Chiesi, F. Ciccia, G. De Leo, and R. Alessandro. 2013. Exosomes as intercellular signaling organelles involved in health and disease: Basic science and clinical applications. Int. J. Mol. Sci. 14:5338-5366.

Crookenden, M. A., C. G. Walker, H. Peiris, Y. Koh, F. Almughlliq, K. Vaswani, S. Reed, A. Heiser, J. J. Loor, J. K. Kay, S. Meier, S. S. Donkin, A. Murray, V. S. R. Dukkipati, J. R. Roche, and M. D. Mitchell. 2017. Effect of circulating exosomes from transition cows on Madin-Darby bovine kidney cell function. J. Dairy Sci. 100:5687-5700.

Dairy, N. Z. 2016. Animal and herd averages. Accessed Jan. 17, 2018. https://www.dairynz.co.nz/animal/animal-evaluation/animal-and -herd-averages.

Dairy, N. Z. 2017. Breeding values. Accessed Aug. 4, 2017. https:// www.dairynz.co.nz/animal/animal-evaluation/interpreting-the -info/breeding-values/.

de Menezes-Neto, A., M. J. Saez, I. Lozano-Ramos, J. Segui-Barber, L. Martin-Jaular, J. M. Ullate, C. Fernandez-Becerra, F. E. Borras, and H. A. Del Portillo. 2015. Size-exclusion chromatography as a stand-alone methodology identifies novel markers in mass spectrometry analyses of plasma-derived vesicles from healthy individuals. J. Extracell. Vesicles 4:27378.

Formigoni, A., and E. Trevisi. 2003. Transition cow: Interaction with fertility. Vet. Res. Commun. 27(Suppl. 1):143-152.

Gautier, A., F. Le Gac, and J. J. Lareyre. 2011. The gsdf gene locus harbors evolutionary conserved and clustered genes preferentially expressed in fish previtellogenic oocytes. Gene 472:7-17. 
Glister, C., N. Hatzirodos, K. Hummitzsch, P. G. Knight, and R. J. Rodgers. 2014. The global effect of follicle-stimulating hormone and tumour necrosis factor $\alpha$ on gene expression in cultured bovine ovarian granulosa cells. BMC Genomics 15:72.

Gray, C. A., C. A. Abbey, P. D. Beremand, Y. Choi, J. L. Farmer, D. L. Adelson, T. L. Thomas, F. W. Bazer, and T. E. Spencer. 2006. Identification of endometrial genes regulated by early pregnancy, progesterone, and interferon tau in the ovine uterus. Biol. Reprod. 74:383-394.

Heneberg, P. 2016. Paracrine tumor signaling induces transdifferentiation of surrounding fibroblasts. Crit. Rev. Oncol. Hematol. 97:303-311.

Karsch, F. J., D. F. Battaglia, K. M. Breen, N. Debus, and T. G. Harris. 2002. Mechanisms for ovarian cycle disruption by immune/ inflammatory stress. Stress 5:101-112.

Kobayashi, M., C. Salomon, J. Tapia, S. E. Illanes, M. D. Mitchell, and G. E. Rice. 2014. Ovarian cancer cell invasiveness is associated with discordant exosomal sequestration of Let-7 miRNA and miR200. J. Transl. Med. 12:4.

Koch, J. M., J. Ramadoss, and R. R. Magness. 2010. Proteomic profile of uterine luminal fluid from early pregnant ewes. J. Proteome Res. 9:3878-3885.

Koh, Y. Q., H. N. Peiris, K. Vaswani, S. Meier, C. R. Burke, K. A. Macdonald, J. R. Roche, F. Almughlliq, B. J. Arachchige, S. Reed, and M. D. Mitchell. 2017. Characterization of exosomes from body fluids of dairy cows. J. Anim. Sci. 95:3893-3904.

Koistinen, H., R. L. Easton, P. C. Chiu, S. Chalabi, M. Halttunen, A Dell, H. R. Morris, W. S. Yeung, M. Seppala, and R. Koistinen. 2003. Differences in glycosylation and sperm-egg binding inhibition of pregnancy-related glycodelin. Biol. Reprod. 69:1545-1551.

Koniusz, S., A. Andrzejewska, M. Muraca, A. K. Srivastava, M. Janowski, and B. Lukomska. 2016. Extracellular vesicles in physiology, pathology, and therapy of the immune and central nervous system, with focus on extracellular vesicles derived from mesenchymal stem cells as therapeutic tools. Front. Cell. Neurosci. 10:109.

Lötvall, J., A. F. Hill, F. Hochberg, E. I. Buzas, D. Di Vizio, C. Gardiner, Y. S. Gho, I. V. Kurochkin, S. Mathivanan, P. Quesenberry, S. Sahoo, H. Tahara, M. H. Wauben, K. W. Witwer, and C. Thery. 2014. Minimal experimental requirements for definition of extracellular vesicles and their functions: A position statement from the International Society for Extracellular Vesicles. J. Extracell. Vesicles 3:26913.

McDougall, S., R. Macaulay, and C. Compton. 2007. Association between endometritis diagnosis using a novel intravaginal device and reproductive performance in dairy cattle. Anim. Reprod. Sci. 99:9-23.

McGough, I. J., and J. P. Vincent. 2016. Exosomes in developmental signalling. Development 143:2482-2493.

Meier, S., B. Fisher, K. Eketone, L. R. McNaughton, P. R. Amer, P. Beatson, J. R. Bryant, K. G. Dodds, R. Spelman, J. R. Roche, and C. R. Burke. 2017. Calf and heifer development and the onset of puberty in dairy cows with divergent genetic merit for fertility. Proc. N.Z. Soc. Anim. Prod. 77:205-210.

Mi, H., S. Poudel, A. Muruganujan, J. T. Casagrande, and P. D. Thomas. 2016. PANTHER version 10: Expanded protein families and functions, and analysis tools. Nucleic Acids Res. 44(D1):D336D342.

Mitchell, M. D., K. Scholz-Romero, S. Reed, H. N. Peiris, Y. Q. Koh, S. Meier, C. G. Walker, C. R. Burke, J. R. Roche, G. Rice, and C. Salomon. 2016. Plasma exosome profiles from dairy cows with divergent fertility phenotypes. J. Dairy Sci. 99:7590-7601.

Nakamura, K., K. Kusama, R. Bai, T. Sakurai, K. Isuzugawa, J. D. Godkin, Y. Suda, and K. Imakawa. 2016. Induction of IFNT-stimulated genes by conceptus-derived exosomes during the attachment period. PLoS One 11:e0158278.

Piccinini, R., E. Binda, M. Belotti, G. Casirani, and A. Zecconi. 2004. The evaluation of non-specific immune status of heifers in field conditions during the periparturient period. Vet. Res. 35:539-550.

Pohler, K. G., J. A. Green, L. A. Moley, S. Gunewardena, W. T. Hung, R. R. Payton, X. Hong, L. K. Christenson, T. W. Geary, and M. F.
Smith. 2017. Circulating microRNA as candidates for early embryonic viability in cattle. Mol. Reprod. Dev. 84:731-743.

Rappsilber, J., Y. Ishihama, and M. Mann. 2003. Stop and go extraction tips for matrix-assisted laser desorption/ionization, nanoelectrospray, and LC/MS sample pretreatment in proteomics. Anal. Chem. 75:663-670.

Reed, C. B., S. Meier, J. L. Pitman, and C. R. Burke. 2017. Oocyte maturation and quality in dairy heifers with diverse genetic merit for fertility. Proc. N.Z. Soc. Anim. Prod. 77:29-33.

Reinhardt, T. A., J. D. Lippolis, B. J. Nonnecke, and R. E. Sacco. 2012. Bovine milk exosome proteome. J. Proteomics 75:1486-1492.

Reinhardt, T. A., R. E. Sacco, B. J. Nonnecke, and J. D. Lippolis. 2013. Bovine milk proteome: Quantitative changes in normal milk exosomes, milk fat globule membranes and whey proteomes resulting from Staphylococcus aureus mastitis. J. Proteomics 82:141-154.

Rizos, D., V. Maillo, and P. Lonergan. 2016. Role of the oviduct and oviduct-derived products in ruminant embryo development. Anim. Reprod. 13:160-167.

Roche, J. R., C. R. Burke, S. Meier, and C. G. Walker. 2011. Nutrition $\times$ reproduction interaction in pasture-based systems: Is nutrition a factor in reproductive failure? Anim. Prod. Sci. 51:1045-1066.

Roche, J. R., P. G. Dillon, C. R. Stockdale, L. H. Baumgard, and M. J. VanBaale. 2004. Relationships among international body condition scoring systems. J. Dairy Sci. 87:3076-3079.

Salomon, C., M. J. Torres, M. Kobayashi, K. Scholz-Romero, L. Sobrevia, A. Dobierzewska, S. E. Illanes, M. D. Mitchell, and G. E. Rice. 2014. A gestational profile of placental exosomes in maternal plasma and their effects on endothelial cell migration. PLoS One 9:e98667.

Seppälä, M., H. Koistinen, R. Koistinen, A. Dell, H. R. Morris, S. Oehninger, and G. F. Clark. 1997. Glycodelins as regulators of early events of reproduction. Clin. Endocrinol. (Oxf.) 46:381-386.

Seppälä, M., R. N. Taylor, H. Koistinen, R. Koistinen, and E. Milgrom. 2002. Glycodelin: A major lipocalin protein of the reproductive axis with diverse actions in cell recognition and differentiation. Endocr. Rev. 23:401-430.

Spencer, T. E., G. A. Johnson, R. C. Burghardt, and F. W. Bazer. 2004. Progesterone and placental hormone actions on the uterus: Insights from domestic animals. Biol. Reprod. 71:2-10.

Strucken, E. M., R. H. Bortfeldt, J. Tetens, G. Thaller, and G. A. Brockmann. 2012. Genetic effects and correlations between production and fertility traits and their dependency on the lactationstage in Holstein Friesians. BMC Genet. 13:108.

Taheripanah, R., M. Zamaniyan, S. Akhoondzadeh, A. Taheripanah, and N. Malih. 2017. Uterine and serum glycodelin concentration in recurrent implantation failure versus normal fertile women on implantation window. Int. J. Women's Health Reprod. Sci. 5:103-106.

Tranguch, S., J. Cheung-Flynn, T. Daikoku, V. Prapapanich, M. B. Cox, H. R. Xie, H. B. Wang, S. K. Das, D. F. Smith, and S. K. Dey. 2005. Cochaperone immunophilin FKBP52 is critical to uterine receptivity for embryo implantation. Proc. Natl. Acad. Sci USA 102:14326-14331.

Tsukahara, F., M. Hattori, T. Muraki, and Y. Sakaki. 1996. Identification and cloning of a novel cDNA belonging to tetratricopeptide repeat gene family from Down syndrome-critical region 21q22.2. J. Biochem. 120:820-827.

Uchida, H., T. Maruyama, T. Nagashima, H. Asada, and Y. Yoshimura. 2005. Histone deacetylase inhibitors induce differentiation of human endometrial adenocarcinoma cells through up-regulation of glycodelin. Endocrinology 146:5365-5373.

Uchida, H., T. Maruyama, S. Nishikawa-Uchida, K. Miyazaki, H. Masuda, and Y. Yoshimura. 2013. Glycodelin in reproduction. Reprod. Med. Biol. 12:79-84.

Vaswani, K., K. Ashman, S. Reed, C. Salomon, S. Sarker, J. A. Arraztoa, A. Perez-Sepulveda, S. E. Illanes, D. Kvaskoff, M. D. Mitchell, and G. E. Rice. 2015. Applying SWATH mass spectrometry to investigate human cervicovaginal fluid during the menstrual cycle. Biol. Reprod. 93:39.

Weaver, A. 2017. Autocrine role of exosomes in cellular adhesion, migration, and invasion. Biophys. J. 112:38a. (Abstr.) 
Xu, Y., J. Cao, S. Huang, D. Feng, W. Zhang, X. Zhu, and X. Yan. 2015. Characterization of tetratricopeptide repeat-containing proteins critical for cilia formation and function. PLoS One 10:e0124378

Yang, Z., I. M. Wolf, H. Y. Chen, S. Periyasamy, Z. A. Chen, W. D. Yong, S. Shi, W. H. Zhao, J. M. Xu, A. Srivastava, E. R. Sanchez, and W. N. Shou. 2006. FK506-binding protein 52 is essential to uterine reproductive physiology controlled by the progesterone receptor A isoform. Mol. Endocrinol. 20:2682-2694.

Yocum, A. K., and A. M. Chinnaiyan. 2009. Current affairs in quantitative targeted proteomics: Multiple reaction monitoring-mass spectrometry. Brief. Funct. Genomic Proteomic 8:145-157.
Yu, Y., Z. Zhao, Y. Shi, H. Tian, L. Liu, X. Bian, Y. Xu, X. Zheng, L. Gan, Y. Shen, C. Wang, X. Yu, C. Wang, X. Zhang, X. Guo, J. Wang, H. Ikehashi, L. Jiang, and J. Wan. 2016. Hybrid sterility in rice (Oryza sativa L.) involves the tetratricopeptide repeat domain containing protein. Genetics 203:1439-1451.

Zduriencikova, M., P. Gronesova, D. Cholujova, and J. Sedlak. 2015. Potential biomarkers of exosomal cargo in endocrine signaling. Endocr. Regul. 49:141-150.

Zeytuni, N., and R. Zarivach. 2012. Structural and functional discussion of the tetra-trico-peptide repeat, a protein interaction module. Structure 20:397-405. 